\title{
Spectrofluorometric Analysis of New-Generation Antidepressant Drugs in Pharmaceutical Formulations, Human Urine, and Plasma Samples
}

\author{
Ruchita S. Das and Y. K. Agrawal \\ Institute of Research \& Development, Gujarat Forensic Sciences University, Sector 18-A, \\ Gandhinagar 382007, India
}

Correspondence should be addressed to Ruchita S. Das, das_ruchita@yahoo.com

Copyright (C) 2012 R. S. Das and Y. K. Agrawal. This is an open access article distributed under the Creative Commons Attribution License, which permits unrestricted use, distribution, and reproduction in any medium, provided the original work is properly cited.

\begin{abstract}
Spectrofluorometric analysis for the quantification of new-generation antidepressant drugs belong to the class of selective serotonin reuptake inhibitors and selective norepinephrine reuptake inhibitors is described. Five different drugs, sertraline, paroxetine, citalopram, venlafaxine, and fluoxetine, were analysed for spectrofluorometric detection in pharmaceutical formulations and urine and plasma samples. The calibration curves were found linear between fluorescence intensity and drugs concentration in the range of $5-500 \mathrm{ng} / \mu \mathrm{L}$ with coefficients of determination above 0.9985 for all the analytes. The method recoveries were higher than $85 \%$ in all the three matrices. The intra- and interday variation coefficients were observed less than $8 \%$ and $13 \%$, respectively. The limits of detection (LOD) and limit of quantification (LOQ) were found in the range of $0.016-0.084 \mathrm{ng} / \mu \mathrm{L}$ and $0.090-0.285 \mathrm{ng} / \mu \mathrm{L}$, respectively. Additionally, the results were compared statistically for each analyte in all the three matrices and were found equivalent, which signifies the absence of matrix effect. Thus, the method will be applied successfully to the determination of the cited drugs in pure or dosage forms as well as in biological fluids with good accuracy and precision.
\end{abstract}

Keywords: Analysis, antidepressant drugs, pharmaceutical formulations, plasma, spectrofluorometer, urine

\section{Introduction}

Antidepressant drugs represent the first choice in the treatment of moderate to severe depressive illness like stress and anxiety disorders and obsessive-compulsive disorder Antidepressants cover varieties of drugs having different modes of actions towards certain neurotransmitter receptors and transporters. They are also often characterized as $1 \mathrm{st}, 2 \mathrm{nd}$, and $3 \mathrm{rd}$ or new generation depending on when they were developed [1]. The new-generation antidepressant drugs are the most widespread class of drugs and are in fact becoming the drugs of first choice for the treatment of depressive disorders, because they are considered to be more potent than other antidepressant groups. The highly prescribed classes 
of this category are selective serotonin re-uptake inhibitors (SSRIs) and selective norepinephrine reuptake inhibitors (SNRIs) [2]. The commonly administered drugs of these two classes are sertraline (SER), paroxetine (PAR), fluoxetine (FLX), citalopram (CIT) (SSRIs) and venlafaxine (VLF) (SNRI), given for the treatment of major depressive disorders (Figure 1). The therapeutic drug monitoring of antidepressants provides the possibility to reduce side effects and optimize the treatment of patients with depression. Hence, there is a need to develop simple, reliable, fast, and sensitive analytical methods for the determination of these agents in pharmaceutical formulations and biological matrices.

Several methods have been reported for their determination in biological matrices like gas chromatography (GC) [3, 4], high-performance liquid chromatography (HPLC) [5, 6], liquid chromatography tandem mass spectrometry (LC-MS/MS) [7, 8], and micellar electrokinetic capillary chromatography $[9,10]$. However, their sophisticated instrumentation and high analysis cost limited their routine use in analytical laboratories.

Therefore, development of alternative methods for routine analysis is desirable. Thus, the purpose of this work is to develop simple, rapid, and sensitive method for the determination of the abovementioned drugs in biological fluids using a spectrofluorometric technique.

Spectrofluorometry is considered as one of the convenient analytical techniques because of its simplicity, low cost, and wide availability in most laboratories. It measures the fluorescent property (emission) of compounds. The emission intensity of an emitting substance is linearly proportional to analyte concentration and, thus, became a useful tool for quantification of such species [11]. The selectivity provided by spectrofluorometers is of prime importance to investigations concerned with the electronic and structural characteristics of molecules and is of great value in qualitative and quantitative analysis and bioanalytical works.

In the literature, very few spectrophotometric methods have been reported for the determination of new-generation antidepressant drugs in tablet dosage forms and biological fluids. These methods are costlier as they require a variety of expensive chemicals [12]. Some are based on formation of an ionpair complex by reacting with bromocresol green (BCG), bromophenol blue (BPB), and bromothymol blue (BTB) [13]; while some are based upon the formation of charge transfer complexes with chloranil, 2, -3 dichloro-5, -6-dicyanoquinone and iodine [14]. Also, few are based on the reaction of the N-alky lvinylamine formed from the interaction of the free secondary amino group of the drug with 3 types of haloquinones (chloranil, bromanil, and 2,3-dichloronaphthoquinone) to give coloured vinylaminosubstituted quinines [15]. Furthermore, the analytical reactions are very long and the procedures are also time consuming.

To the best of our knowledge, no spectrofluorometric method has been developed for the determination of SSRIs and SNRI in both the biological fluids (urine and blood), especially without using any chemical solvents. Thus, this paper represents the method for the analysis of SER, PAR, CIT, VLF, and PAR in pharmaceutical formulation and urine and plasma samples.

\section{Materials and Methodology}

\subsection{Chemicals}

Sertraline, paroxetine, fluoxetine, and venlafaxine were kindly provided by Zydus Cadila Pharmaceutical (Ahmadabad, India). Citalopram was provided by Torrent Pharmaceuticals (Ahmadabad, India). Tablets 
<smiles>Fc1ccc([C@H]2CCNC[C@H]2COc2ccc3c(c2)OCO3)cc1</smiles><smiles>CNCCC(Oc1ccc(C(F)(F)F)cc1)c1ccccc1</smiles><smiles></smiles><smiles>CN[C@H]1CC[C@@H](c2ccc(Cl)c(Cl)c2)c2ccccc21</smiles><smiles>COc1ccc(C(CN(C)C)C2(O)CCCCC2)cc1</smiles>

Paroxetine

[(3S-trans)-3-((1, 3-benzodioxol-5phenyloxy)methyl)-4-(4fluorophenyl)-piperidine]

Fluoxetine

[N-methyl-3-phenyl-3-[4trifluoromethyl)phenoxy]-propan-1amine]

\section{Citalopram}

[(RS)-1-[2-dimethylamino-1-(4methoxyphenyl)-ethyl]cyclohexanol]

Sertraline

[(1S, 4S)-4(3, 4-dichlorophenyl)-Nmethyl-1, 2, 3, 4-tetrahydronapthalen-1amine]

Venlafaxine

[1-[2-dimethylamino-1-(4methoxyphenyl)ethyl]cyclohe xan-1-ol]

Figure 1: Chemical structures of SSRIs and SNRI antidepressant drugs.

were procured from different companies, sertraline Actiser $25 \mathrm{mg}$ (Unimark Pharma, Chandigarh, India); citalopram C-pram $10 \mathrm{mg}$ (Unichem, Zirakpur, India); paroxetine Cinpar-CR $25 \mathrm{mg}$ (Cinerea, Chandigarh, India); fluoxetine Afzot 20 mg (Pfizer, Mumbai, India); venlafaxine FAXIVEN-XR 37.5 mg (Triton, Chennai, India). Aqueous solutions were prepared in Milli-Q water from a Millipore Purification 
Table 1: Excitation and emission wavelengths.

\begin{tabular}{lccc}
\hline S. Number & Analyte & $\lambda_{\mathrm{ex}}(\mathrm{nm})$ & $\lambda_{\mathrm{emi}}(\mathrm{nm})$ \\
\hline$(1)$ & Sertraline (SER) & 280 & 560 \\
$(2)$ & Paroxetine (PAR) & 244 & 339 \\
$(3)$ & Citalopram (CIT) & 230 & 300 \\
$(4)$ & Venlafaxine (VLF) & 240 & 302 \\
$(5)$ & Fluoxetine (FLX) & 220 & 294 \\
\hline
\end{tabular}

$\lambda_{\mathrm{ex}}=$ excitation wavelength and $\lambda_{\mathrm{emi}}=$ emission wavelength.

system and all experiments were performed at room temperature. Whatman filter paper no. 42 was used to filter the solutions.

\subsection{Biological Samples}

Urine was collected from healthy volunteers in normal conditions, while blood was procured through a local blood bank from which plasma was separated after centrifugation for analysis. The samples were stored in appropriate polytetrafluoro-ethylene (PTPE) flasks at $-20^{\circ} \mathrm{C}$ until analysed.

\subsection{Spectroauorometry Conditions}

Spectrofluorometric analysis was performed with a Jasco FP-6500 spectrofluorometer. Measurements were performed with $10 \mathrm{~mm}$ quartz cell. It consists of two monochromators, which selects two types of wavelengths as excitation and emission (fluorescence). Fluorometeric cuvetts are made of quartz and are clear on all sides ( 2 opaque sides in UV). Excitation and emission wavelengths were set according to the analysis of individual analytes, summarised in Table 1. Xenon flash lamp was used as a light source. Data acquisition and analysis were performed using standard software supplied by the manufacturer. Figure 2 shows emission spectra of all the analytes. In an emission spectrum (fluorescence), a fixed wavelength is used to excite the molecules, and the intensity of the emitted radiation is monitored as a function of wavelength.

\subsection{Standard Preparation}

Standard or stock solutions of all the analytes were prepared by dissolving $10 \mathrm{mg}$ in $10 \mathrm{~mL}$ of water in order to get $1000 \mathrm{ng} / \mu \mathrm{L}$ of the stock solution. The working solutions of drugs $(5-500 \mathrm{ng} / \mu \mathrm{L})$ were prepared from the stock solution by dilution with distil water each day. Stock and reference standard solutions were stored and protected from light at $4{ }^{\circ} \mathrm{C}$ for 6 months.

\subsection{Sample Preparation for Estimation of All the Analytes in Tablet Dosage Forms}

Analyses of tablet formulation for all the drugs were obtained by [using ten tablets accordingly the analysis of a particular compound]. The tablets were crushed to furnish a homogeneous powder and 


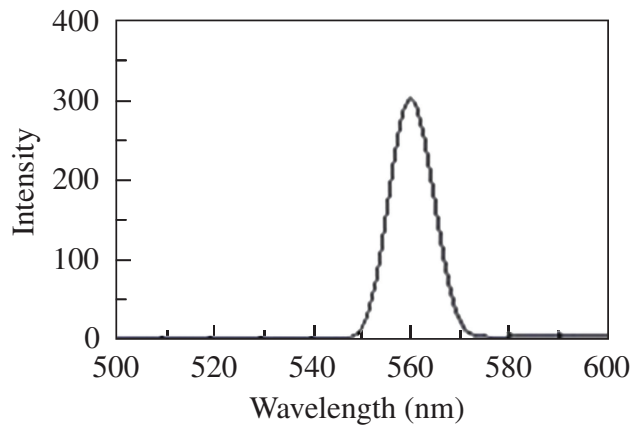

(a)

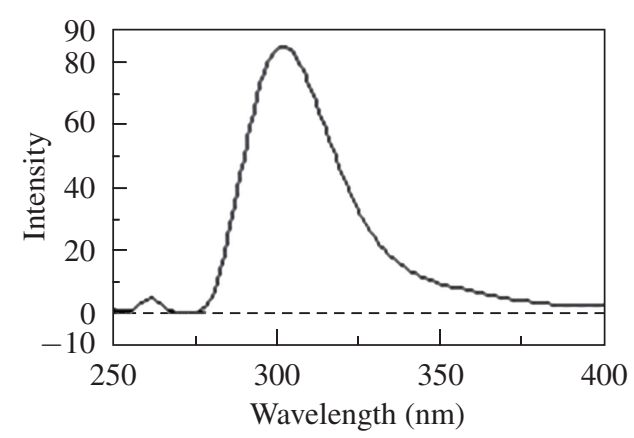

(c)

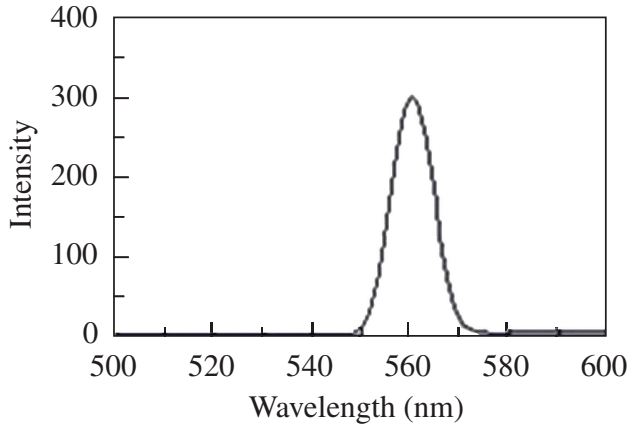

(b)

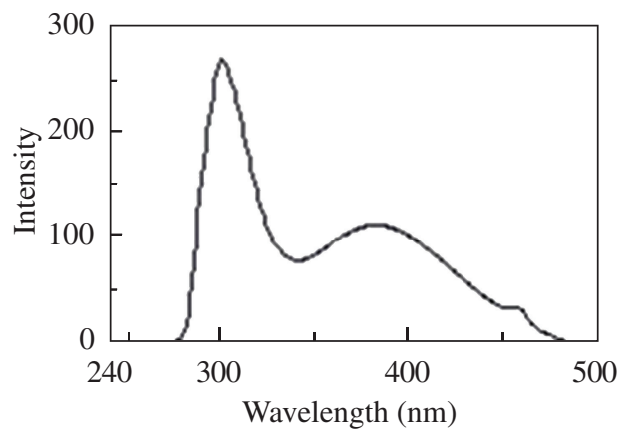

(d)

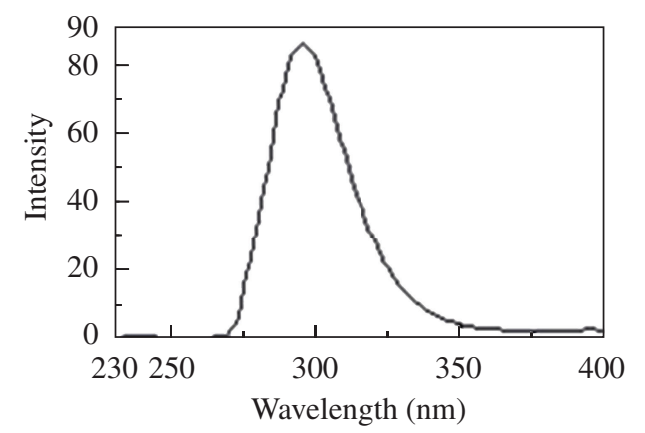

(e)

Figure 2: Emission spectra of (a) sertraline, (b) paroxetine, (c) venlafaxine, (d) citalopram, and (e) fluoxetine.

quantity equivalent to $10 \mathrm{mg}$ weighed in $10 \mathrm{~mL}$ of volumetric flask and dissolved with water which formed $1000 \mathrm{ng} / \mu \mathrm{L}$ of stock solution. The solution was filtered through Whatmann filter paper no. 42. An appropriate volume of filtrate was diluted with water so that the concentration of all the analytes in the final solution was within the working range. All stock solutions were stored at $4^{\circ} \mathrm{C}$ and were found stable for 3 months. The excitation and emission wavelengths were set accordingly for each analyte, as mentioned in Table 1. 
Table 2: Regression data for all the analytes.

\begin{tabular}{lccccc}
\hline Parameters & SER & PAR & CIT & VLF & FLX \\
\hline Range $(\mathrm{ng} / \mu \mathrm{L})$ & $5-500$ & $10-500$ & $5-500$ & $10-500$ & $10-500$ \\
Regression equation $\left(Y^{\mathrm{a}}\right)$ & & & & & \\
$\quad$ Slope $(b)$ & 16.04 & 7.990 & 14.32 & 3.960 & 3.610 \\
$\quad$ Intercept $(c)$ & 6.0 & 1.50 & 2.60 & 4.70 & 3.30 \\
Correlation coefficient $\left(r^{2}\right)$ & 0.9995 & 0.9990 & 0.9992 & 0.9986 & 0.9989 \\
$\mathrm{LOD}^{\mathrm{c}}(\mathrm{ng} / \mu \mathrm{L})$ & 0.018 & 0.035 & 0.016 & 0.063 & 0.084 \\
$\mathrm{LOQ}^{\mathrm{d}}(\mathrm{ng} / \mu \mathrm{L})$ & 0.090 & 0.108 & 0.048 & 0.186 & 0.285 \\
\hline
\end{tabular}

${ }^{\mathrm{a}} Y=b X+c$, where " $X$ " is concentration in $\mu \mathrm{g} / \mathrm{mL}$, and $Y$ is an emission unit. ${ }^{\mathrm{c}}$ Limit of detection $(\mathrm{LOD})=3.3 \times \mathrm{S} . \mathrm{D} / \mathrm{slope}$,

${ }^{\mathrm{d}}$ limit of quantification $(\mathrm{LOQ})=10 \times$ S.D $/$ slope.

\subsection{Sample Preparation for Estimation of All the Analytes in Urine and Plasma}

$1 \mathrm{~mL}$ urine sample, $5 \mathrm{mg}$ of tartaric acid (for protein precipitation), and $1 \mathrm{~mL}$ of stock solution $(1000 \mathrm{ng} / \mu \mathrm{L})$ were combined and centrifuged at $3000 \mathrm{rpm}$ for $15 \mathrm{~min}$. The clear supernatant was used in further analysis. The supernatant was diluted ten times with distilled water. This dilution was used for the preparation of specific urine drug concentration between 10 and $100 \mathrm{ng} / \mu \mathrm{L}$. Simultaneously, blank samples were also prepared without spiking the drug. The fluorescence intensity was measured for each analyte on spectrofluorometer at a specific emission and excitation wavelengths (Table 1), and the concentration was calculated from the regression equation.

Plasma samples were prepared by spiking $1 \mathrm{~mL}$ of the sample with the $0.5 \mathrm{~mL}$ of standard solution $(1000 \mathrm{ng} / \mu \mathrm{L})$ of the analyte of interest. This spiked sample was treated with $1 \mathrm{~mL}$ of acetonitrile and $1 \mathrm{~mL}$ of methanol to precipitate the proteins and then centrifuged at $3000 \mathrm{rpm}$ for $20 \mathrm{~min}$. The supernatant was transferred to $10 \mathrm{~mL}$ of volumetric flask, and then evaporated to dryness. The residue was reconstituted with the water up to the mark. This dilution was used for the preparation of specific plasma drug concentration between 10 and $100 \mathrm{ng} / \mu \mathrm{L}$. The blank sample was also prepared without spiking the drug. Then the relative fluorescence for each concentration was recorded, and the concentration was calculated from the regression equation.

\subsection{Validation of the Methods}

ICH guidelines for method validation were followed $[16,17]$. The concentration range (linearity) was estimated on the basis of the regression curve $(y=a x+b)$, and correlation coefficient $\left(r^{2}\right)$ obtained from the reference standard solutions of the drugs $(n=6)$. To study the accuracy of the proposed methods and to check the interference from excipients present in the dosage form, recovery experiments were carried out by the standard addition method at three different levels. A known amount of drug was added to preanalyzed tablet powder, and percentage recoveries were calculated. Similarly, for accurate determination of SSRIs and SNRI in urine and plasma samples, standard addition method was applied. The recovery of the drugs was determined at three different concentrations of biological samples (urine and plasma). The recoveries were calculated by comparing the concentration obtained from the spiked samples with that of each pure drug. 
Table 3: Evaluation of accuracy and precision of the proposed method in pharmaceutical formulations.

\begin{tabular}{lcccc}
\hline \multirow{2}{*}{ Amount added $(\mathrm{ng} / \mathrm{mL})$} & $\begin{array}{c}\text { Found } \\
(\mathrm{ng} / \mu \mathrm{L}) \pm \mathrm{SD}^{1}\end{array}$ & $\begin{array}{c}\text { Intraday Recovery } \\
\pm \mathrm{RSD}^{3}\end{array}$ & $\begin{array}{c}\text { Found } \\
(\mathrm{ng} / \mu \mathrm{L}) \pm \mathrm{SD}^{1}\end{array}$ & $\begin{array}{c}\text { Interday } \\
\pm \mathrm{RSD}^{3}\end{array}$ \\
\hline SER & $9.38 \pm 0.095$ & $93.80 \pm 1.83$ & $8.50 \pm 0.062$ & $85.0 \pm 2.79$ \\
10 & $49.25 \pm 0.089$ & $98.50 \pm 3.51$ & $47.42 \pm 0.106$ & $94.84 \pm 3.98$ \\
50 & $98.97 \pm 0.065$ & $98.57 \pm 5.71$ & $98.98 \pm 0.077$ & $98.98 \pm 5.04$ \\
100 & & & & \\
\hline PAR & $9.43 \pm 0.066$ & $94.30 \pm 1.36$ & $09.08 \pm 0.176$ & $90.80 \pm 1.45$ \\
10 & $49.05 \pm 0.087$ & $98.10 \pm 2.73$ & $49.07 \pm 0.096$ & $98.14 \pm 3.55$ \\
50 & $99.44 \pm 0.061$ & $99.44 \pm 4.58$ & $98.88 \pm 0.138$ & $98.88 \pm 5.38$ \\
100 & & & & \\
CIT & $9.80 \pm 0.050$ & $98.0 \pm 1.65$ & $8.32 \pm 0.159$ & $83.20 \pm 2.26$ \\
10 & $48.89 \pm 0.070$ & $97.78 \pm 2.15$ & $48.89 \pm 0.111$ & $97.78 \pm 5.17$ \\
50 & $99.17 \pm 0.033$ & $99.17 \pm 5.11$ & $98.22 \pm 0.109$ & $98.22 \pm 6.43$ \\
100 & & & & \\
VLF & & & & \\
10 & $8.57 \pm 0.104$ & $85.70 \pm 2.45$ & $8.66 \pm 0.130$ & $86.60 \pm 1.13$ \\
50 & $48.59 \pm 0.076$ & $97.18 \pm 3.12$ & $47.69 \pm 0.153$ & $95.38 \pm 4.17$ \\
100 & $98.98 \pm 0.126$ & $98.98 \pm 3.87$ & $98.84 \pm 0.111$ & $98.84 \pm 5.43$ \\
\hline FLX & & & \\
10 & $8.70 \pm 0.078$ & $87.0 \pm 1.39$ & $7.90 \pm 0.026$ & $79.0 \pm 2.92$ \\
50 & $48.77 \pm 0.103$ & $97.54 \pm 2.73$ & $48.54 \pm 0.165$ & $97.08 \pm 5.74$ \\
100 & $98.69 \pm 0.076$ & $98.69 \pm 5.91$ & $97.74 \pm 0.053$ & $98.69 \pm 6.19$ \\
\hline
\end{tabular}

${ }^{1}$ Average of six replicate determinations and their standard deviation, ${ }^{2}$ RSD: relative standard deviation.

The experiments were repeated six times in a day at three different concentrations (in triplets) to determine intraday precision and on six different days to determine interday precision in pharmaceutical formulations, urine and plasma samples. Thus, the repeatability and reproducibility were confirmed by repeating the methods at the same and different days. The limit of detection (LOD) and limit of quantification (LOQ) were estimated from the signal-to-noise ratio $(\mathrm{S} / \mathrm{N})$. These limits were defined as the lowest concentration level that provided the fluorescent intensity with signal-to-noise ratio higher than $3: 1$ for detection and $10: 1$ for quantification.

\section{Result and Discussion}

The selected class of antidepressant drugs shows native strong fluorescent character, as they contain isolated aromatic ring or fluorophore in their structure which gives the property of fluorescence. All the analytes are water soluble and emits fluorescence at a particular wavelength when excited at specific wavelength. Thus, by exciting at one wavelength and monitoring the light emitted at the longer emission, wavelength became a very selective way of detecting analytes. 
Table 4: Recovery studies of analytes in pharmaceutical preparations by proposed method.

\begin{tabular}{|c|c|c|c|c|}
\hline Pharmaceutical preparation & $\begin{array}{c}\text { Amount added } \\
(\mathrm{ng} / \mu \mathrm{L})\end{array}$ & $\begin{array}{c}\text { Found }^{1}(\mathrm{ng} / \mu \mathrm{L}) \\
\pm \mathrm{SD}^{1}\end{array}$ & $(\%) \mathrm{RE}^{2}$ & $\begin{array}{c}\text { (\%) Recovery }{ }^{3} \pm \\
\text { RSD }\end{array}$ \\
\hline \multirow{3}{*}{ SER (Tab) } & 10 & $08.95 \pm 0.123$ & 10.5 & $89.50 \pm 2.65$ \\
\hline & 50 & $49.98 \pm 0.126$ & 0.04 & $99.96 \pm 3.17$ \\
\hline & 100 & $100.02 \pm 0.065$ & 0.02 & $100.02 \pm 4.53$ \\
\hline \multirow{3}{*}{ PAR (Tab) } & 10 & $10.02 \pm 0.312$ & 0.20 & $102.0 \pm 2.86$ \\
\hline & 50 & $48.89 \pm 0.256$ & 2.22 & $97.78 \pm 3.53$ \\
\hline & 100 & $98.72 \pm 0.146$ & 1.28 & $98.72 \pm 5.16$ \\
\hline \multirow{3}{*}{ CIT (Tab) } & 10 & $09.88 \pm 0.083$ & 1.20 & $98.80 \pm 1.63$ \\
\hline & 50 & $48.88 \pm 0.192$ & 2.24 & $97.76 \pm 3.78$ \\
\hline & 100 & $98.68 \pm 0.102$ & 1.32 & $98.68 \pm 4.84$ \\
\hline \multirow{3}{*}{ VLF (Tab) } & 10 & $08.78 \pm 0.350$ & 12.2 & $87.80 \pm 1.58$ \\
\hline & 50 & $47.35 \pm 0.048$ & 5.30 & $94.70 \pm 3.12$ \\
\hline & 100 & $96.01 \pm 0.028$ & 3.99 & $96.01 \pm 4.54$ \\
\hline \multirow{3}{*}{ FLX (Tab) } & 10 & $08.66 \pm 0.034$ & 15.4 & $86.60 \pm 2.13$ \\
\hline & 50 & $48.85 \pm 0.058$ & 2.30 & $97.70 \pm 4.89$ \\
\hline & 100 & $97.89 \pm 0.283$ & 2.11 & $97.89 \pm 5.15$ \\
\hline
\end{tabular}

${ }^{1}$ Average of six determinations; ${ }^{2}$ accuracy $(\%$ error $)=$ amount found - amount added/added $\times 100,{ }^{3}$ recovery of amount added to the pharmaceutical formulation (average of six determinations).

Under the optimum experimental conditions of the proposed methods, intensity-concentration plots were found linear over the range of $5-500 \mathrm{ng} / \mu \mathrm{L}$ for all the analytes. These concentrations are in the satisfactory range of clinical or therapeutic as well as toxicological analysis of SSRIs and SNRI drugs [18]. The linear regression data of the proposed method is given in Table 2. LOD and LOQ were evaluated on the basis of S/N ratio of three and ten, respectively. The LOD and LOQ achieved were observed as $0.016-0.084 \mathrm{ng} / \mu \mathrm{L}$ and $0.090-0.285 \mathrm{ng} / \mu \mathrm{L}$, respectively.

\subsection{Analysis of Pharmaceutical Formulations}

Intra-day precision was studied by analyzing repeatedly, on the same day, six replicates of three different concentration levels within linear range. Inter-day precision values were determined from six consecutive days. The experiments performed to determine repeatability (inter-day), it was remarkable that the values of relative standard deviation (RSD) were less than $7 \%$ for each analyte at different concentrations. In the reproducibility study (intra-day), it has been observed that the RSD was less than $12 \%$ for each analyte. The results are summarized in Table 3.

The recoveries of the proposed methods in dosage form of different pharmaceutical preparations were tested for possible interference with standard addition method. The recovery was determined by adding known quantities of pure analytes to a definite amount of preanalysed tablet samples within the analytical concentration range of the proposed method. The added quantities of the individual drugs were estimated by above method. The average percent recoveries (86-102\%) obtained were satisfactory 
Table 5: Evaluation of accuracy and precision of the proposed method in urine.

\begin{tabular}{lcccc}
\hline Amount added $(\mathrm{ng} / \mu \mathrm{L})$ & $\begin{array}{c}\text { Found } \\
(\mathrm{ng} / \mu \mathrm{L}) \pm \mathrm{SD}^{1}\end{array}$ & $\begin{array}{c}\text { Recovery } \\
\pm \mathrm{RSD}^{3}(\%)\end{array}$ & $\begin{array}{c}\text { Found } \\
(\mathrm{ng} / \mu \mathrm{L}) \pm \mathrm{SD}^{1}\end{array}$ & $\begin{array}{c}\text { Recovery } \\
\pm \mathrm{RSD}^{3}(\%)\end{array}$ \\
\hline SER & $08.80 \pm 0.077$ & $88.0 \pm 2.08$ & $08.97 \pm 0.163$ & $89.70 \pm 2.17$ \\
10 & $49.34 \pm 0.096$ & $98.69 \pm 3.19$ & $48.45 \pm 0.026$ & $96.90 \pm 3.68$ \\
50 & $98.05 \pm 0.044$ & $98.05 \pm 4.22$ & $98.25 \pm 0.016$ & $98.25 \pm 4.26$ \\
100 & & & & \\
\hline PAR & $08.40 \pm 0.096$ & $84.0 \pm 1.25$ & $08.70 \pm 0.115$ & $87.0 \pm 2.90$ \\
10 & $48.35 \pm 0.092$ & $96.70 \pm 4.49$ & $47.66 \pm 0.019$ & $95.32 \pm 5.71$ \\
50 & $98.11 \pm 0.068$ & $98.11 \pm 5.06$ & $98.19 \pm 0.120$ & $98.19 \pm 5.11$ \\
100 & & & & \\
CIT & $09.09 \pm 0.059$ & $90.90 \pm 2.07$ & $08.29 \pm 0.093$ & $82.90 \pm 1.70$ \\
10 & $48.92 \pm 0.068$ & $97.84 \pm 3.19$ & $48.15 \pm 0.112$ & $96.30 \pm 4.70$ \\
50 & $97.62 \pm 0.663$ & $97.62 \pm 5.16$ & $96.51 \pm 0.054$ & $96.51 \pm 6.89$ \\
100 & & & & \\
VLF & & & & \\
10 & $08.70 \pm 0.084$ & $87.0 \pm 2.94$ & $08.70 \pm 0.093$ & $87.0 \pm 1.83$ \\
50 & $48.07 \pm 0.113$ & $96.34 \pm 4.15$ & $47.22 \pm 0.156$ & $94.44 \pm 5.48$ \\
100 & $97.03 \pm 0.079$ & $97.03 \pm 4.27$ & $96.21 \pm 0.102$ & $96.21 \pm 4.95$ \\
\hline FLX & & & & \\
10 & & & & \\
50 & & & & \\
100 & $47.46 \pm 0.105$ & $84.60 \pm 1.43$ & $09.58 \pm 0.161$ & $95.80 \pm 2.25$ \\
\hline
\end{tabular}

${ }^{1}$ Average of six replicate determinations and their standard deviation (SD); ${ }^{2} \mathrm{RSD}$ : relative standard deviation.

and with good agreement with the labelled amount (Table 4). This shows accuracy of the developed method for selected drugs in commercial pharmaceutical preparations.

\subsection{Analysis of Spiked Urine and Plasma Samples}

It has been found that after oral administration, the bioavailability of all the analytes is more than $70 \%$. About 20\% remains in the unchanged form and execrated in urine, while plasma level concentration is about $20-200 \mathrm{ng} / \mu \mathrm{L}$ [18]. Thus, the concentration range selected for the precision and recovery study is within therapeutic as well as toxicological range for all the analytes in biofluids. The recovery percent and standard deviations (SD) revealed excellent accuracy. Intra-day and inter-day precision study were determined from spiked urine and plasma samples at three different concentrations in triplicate. The experiments performed to determine repeatability (inter-day), it was remarkable that the values of RSD were less than $8 \%$ for each analyte at different concentrations both in urine and plasma. In the reproducibility study (intra-day), it has been observed that the RSD was less than $12 \%$ for each analyte both in urine and plasma samples (Tables 5 and 6). 
Table 6: Evaluation of accuracy and precision of the proposed method in plasma.

\begin{tabular}{|c|c|c|c|c|}
\hline \multirow[b]{2}{*}{ Amount added $(\mathrm{ng} / \mu \mathrm{L})$} & \multicolumn{2}{|c|}{ Intraday } & \multicolumn{2}{|c|}{ Interday } \\
\hline & $\begin{array}{c}\text { Found } \\
(\mathrm{ng} / \mu \mathrm{L}) \pm \mathrm{SD}^{1}\end{array}$ & $\begin{array}{c}\text { Recovery } \\
\pm \mathrm{RSD}^{3}(\%)\end{array}$ & $\begin{array}{c}\text { Found } \\
(\mathrm{ng} / \mu \mathrm{L}) \pm \mathrm{SD}^{1}\end{array}$ & $\begin{array}{c}\text { Recovery } \\
\pm \operatorname{RSD}^{3}(\%)\end{array}$ \\
\hline \multicolumn{5}{|l|}{$\overline{\text { SER }}$} \\
\hline 10 & $08.75 \pm 0.102$ & $87.50 \pm 1.30$ & $08.90 \pm 0.081$ & $89.0 \pm 1.06$ \\
\hline 50 & $48.37 \pm 0.004$ & $96.74 \pm 3.16$ & $47.68 \pm 0.017$ & $95.36 \pm 4.67$ \\
\hline 100 & $97.23 \pm 0.103$ & $97.23 \pm 4.98$ & $96.83 \pm 0.252$ & $96.83 \pm 5.25$ \\
\hline \multicolumn{5}{|l|}{ PAR } \\
\hline 10 & $08.01 \pm 0.107$ & $80.10 \pm 1.30$ & $08.35 \pm 0.106$ & $83.50 \pm 2.18$ \\
\hline 50 & $48.69 \pm 0.025$ & $97.38 \pm 4.04$ & $47.67 \pm 0.045$ & $95.34 \pm 4.19$ \\
\hline 100 & $98.28 \pm 0.120$ & $98.28 \pm 5.10$ & $96.67 \pm 0.110$ & $96.67 \pm 5.12$ \\
\hline \multicolumn{5}{|l|}{ CIT } \\
\hline 10 & $08.36 \pm 0.020$ & $83.60 \pm 2.19$ & $07.09 \pm 0.184$ & $70.90 \pm 1.70$ \\
\hline 50 & $48.06 \pm 0.084$ & $96.12 \pm 3.30$ & $48.05 \pm 0.062$ & $96.10 \pm 2.50$ \\
\hline 100 & $98.95 \pm 0.172$ & $98.95 \pm 4.67$ & $97.51 \pm 0.074$ & $97.51 \pm 4.79$ \\
\hline \multicolumn{5}{|l|}{ VLF } \\
\hline 10 & $08.84 \pm 0.094$ & $88.40 \pm 2.17$ & $07.70 \pm 0.074$ & $77.0 \pm 2.15$ \\
\hline 50 & $49.77 \pm 0.108$ & $99.54 \pm 2.98$ & $47.82 \pm 0.096$ & $95.64 \pm 3.43$ \\
\hline 100 & $97.90 \pm 0.094$ & $97.90 \pm 5.87$ & $97.11 \pm 0.110$ & $97.11 \pm 5.76$ \\
\hline \multicolumn{5}{|l|}{$\overline{\text { FLX }}$} \\
\hline 10 & $07.06 \pm 0.068$ & $70.60 \pm 1.67$ & $07.87 \pm 0.141$ & $78.70 \pm 2.35$ \\
\hline 50 & $47.04 \pm 0.086$ & $94.08 \pm 3.16$ & $46.02 \pm 0.046$ & $92.04 \pm 4.03$ \\
\hline 100 & $97.07 \pm 0.141$ & $97.07 \pm 4.0$ & $98.60 \pm 0.127$ & $98.60 \pm 5.83$ \\
\hline
\end{tabular}

${ }^{1}$ Average of six replicate determinations and standard deviation; ${ }^{2} \mathrm{RSD}$ : relative standard deviation.

It has also been observed that increase in temperature has negative effect on the fluorescence intensity of the analyte due to the more frequent collisions between the molecule and the solvent increases. Similarly by decreasing solvent viscosity, fluorescence automatically decreases for similar reason. For an analyte with basic functional group, a change in $\mathrm{pH}$ may change the analyte's structure and, therefore, its fluorescence property [11]. Thus, to control such stringent variables all the analyses were performed at room temperature, and water was used as a solvent. Major constituents of urine such as urea and uric acid, have not shown any kind of major interferences which influence the analysis. For accurate and proper quantitative determination of the analyte of interest in urine and plasma samples, standard addition method was used. Recoveries from urine and plasma samples were found satisfactory in the range of $85-103 \%$ (Table 7).

\subsection{Statistical Analysis}

To demonstrate statistically the absence of matrix effect, as well as the applicability of regression analysis, calibration plots were prepared for each analyte by plotting the values between concentration 
Table 7: Recovery studies of analytes in urine and plasma by proposed method.

\begin{tabular}{|c|c|c|c|c|}
\hline \multirow[b]{2}{*}{ Amount added $(\mathrm{ng} / \mu \mathrm{L})$} & \multicolumn{2}{|c|}{ Urine } & \multicolumn{2}{|c|}{ Plasma } \\
\hline & $\begin{array}{c}\text { Found } \\
(\mathrm{ng} / \mu \mathrm{L}) \pm \mathrm{SD}^{1}\end{array}$ & $\begin{array}{c}\text { Recovery } \\
\pm \mathrm{RSD}^{2}(\%)\end{array}$ & $\begin{array}{c}\text { Found } \\
(\mathrm{ng} / \mu \mathrm{L}) \pm \mathrm{SD}^{1}\end{array}$ & $\begin{array}{c}\text { Recovery } \\
\pm \mathrm{RSD}^{2}(\%)\end{array}$ \\
\hline \multicolumn{5}{|l|}{ SER } \\
\hline 10 & $08.88 \pm 0.023$ & $88.80 \pm 2.37$ & $08.61 \pm 0.062$ & $86.10 \pm 2.06$ \\
\hline 50 & $48.15 \pm 0.029$ & $96.30 \pm 4.46$ & $48.56 \pm 0.018$ & $97.12 \pm 4.80$ \\
\hline 100 & $97.02 \pm 0.037$ & $97.02 \pm 4.86$ & $98.06 \pm 0.074$ & $98.06 \pm 5.40$ \\
\hline \multicolumn{5}{|l|}{ PAR } \\
\hline 10 & $08.92 \pm 0.075$ & $89.20 \pm 2.36$ & $08.92 \pm 0.087$ & $89.20 \pm 1.50$ \\
\hline 50 & $51.27 \pm 0.096$ & $102.54 \pm 4.33$ & $49.87 \pm 0.043$ & $99.74 \pm 3.90$ \\
\hline 100 & $98.03 \pm 0.073$ & $98.03 \pm 5.56$ & $98.35 \pm 0.184$ & $98.35 \pm 6.50$ \\
\hline \multicolumn{5}{|l|}{ CIT } \\
\hline 10 & $08.45 \pm 0.049$ & $85.50 \pm 1.65$ & $08.93 \pm 0.046$ & $89.30 \pm 2.70$ \\
\hline 50 & $51.05 \pm 0.059$ & $102.1 \pm 3.15$ & $48.05 \pm 0.039$ & $96.10 \pm 4.50$ \\
\hline 100 & $98.79 \pm 0.042$ & $98.79 \pm 4.91$ & $98.65 \pm 0.025$ & $98.68 \pm 5.30$ \\
\hline \multicolumn{5}{|l|}{ VLF } \\
\hline 10 & $09.08 \pm 0.104$ & $90.80 \pm 2.38$ & $08.51 \pm 0.134$ & $85.10 \pm 1.30$ \\
\hline 50 & $48.81 \pm 0.073$ & $97.62 \pm 4.78$ & $48.32 \pm 0.065$ & $96.64 \pm 4.04$ \\
\hline 100 & $101.87 \pm 0.125$ & $100.87 \pm 5.80$ & $100.15 \pm 0.143$ & $100.15 \pm 5.08$ \\
\hline \multicolumn{5}{|l|}{$\overline{\text { FLX }}$} \\
\hline 10 & $10.30 \pm 0.145$ & $103.00 \pm 1.89$ & $09.22 \pm 0.148$ & $92.20 \pm 1.80$ \\
\hline 50 & $49.75 \pm 0.103$ & $99.50 \pm 4.72$ & $49.17 \pm 0.108$ & $98.34 \pm 4.40$ \\
\hline 100 & $102.98 \pm 0.075$ & $102.98 \pm 5.67$ & $101.32 \pm 0.059$ & $101.32 \pm 5.30$ \\
\hline
\end{tabular}

Table 8: ANOVA analysis demonstrating the absence of matrix effect.

\begin{tabular}{lcc}
\hline Analyte & $F$ ratio* $^{*}$ & $P$ value \\
\hline Sertraline & 0.51 & 0.60 \\
Citalopram & 0.15 & 0.85 \\
Paroxetine & 0.20 & 0.81 \\
Venlafaxine & 0.51 & 0.60 \\
Fluoxetine & 0.46 & 0.63 \\
\hline
\end{tabular}

${ }^{*} F_{\text {critical }}=3.68$.

and emission intensity. Thus, the data obtained were analysed by one-way ANOVA between three groups at $95 \%$ confidence interval. Each group comprised of intensity of the analytes at three different concentrations. The ANOVA analysis allows to accept the null hypothesis that the emission intensity observed for each analyte in three matrices are statistically equivalent, in other words there is absence of matrix effect on emission intensity of each analyte. The results of the ANOVA analysis are depicted in Table 8. 
Although there are number of chromatographic separation procedures were given for the analysis of selected antidepressant drugs in pharmaceutical preparations and urine and plasma. awever such determinations are time consuming and need expertise to handle. Thus, rapid analytical methods are required to save cost, time, and labour of the analysis. Therefore, keeping these aspects in mind a method was developed for the detection of SER, PAR, CIT, VLF, and FLX in bulk dosage form and biological fluids.

\section{Conclusion}

Validation of the proposed method is confirmed statistically by low values of standard deviation, percent coefficient of variation, and standard error. The proposed method is selective and rapid. It does not suffer from any interference due to common excipients of tablets (glucose, starch, talc, lactose, and sucrose) or any constituents of plasma and urine (urea, uric acid). Furthermore, no analytical reagents have been used during the analysis as all the working and standard solutions were prepared in water. The method is simple, cost effective, and does not contain any stringent experimental variables which affect the reliability of the results. Therefore, it is evident from the results that the developed method will be highly useful for routine analysis of sertraline, paroxetine, citalopram, venlafaxine, and fluoxetine in pharmaceutical formulations and urine and plasma and other biological fluids as well.

\section{References}

[1] W. Z. Potter and L. E. Hollister, "Antidepressant agents," in Basic and Clinical Pharmacology, B. G. Katzung, Ed., pp. 475-480, McGraw-Hill, New York, NY, USA, 2007.

[2] H. P. Rang, M. M. Dale, J. M. Ritter, and J. M. Flower, Rang \& Dale s Pharmacology, Elsevier, Churchill Livingstone, 2007.

[3] C. B. Eap, "Simultaneous determination of human plasma levels of citalopram, paroxetine, sertraline, and their metabolites by gas chromatography-mass spectrometry," Journal of Chromatographic Science, vol. 36, no. 7, pp. 365-371, 1998.

[4] T. Gunnar, S. Mykkänen, K. Ariniemi, and P. Lillsunde, "Validated semiquantitative/quantitative screening of 51 drugs in whole blood as silylated derivatives by gas chromatography-selected ion monitoring mass spectrometry and gas chromatography electron capture detection," Journal of Chromatography B, vol. 806, no. 2, pp. 205-219, 2004.

[5] R. Mandrioli, M. A. Saracino, S. Ferrari, D. Berardi, E. Kenndler, and M. A. Raggi, "HPLC analysis of the second-generation antidepressant sertraline and its main metabolite $\mathrm{N}$-desmethylsertraline in human plasma," Journal of Chromatography B, vol. 836, no. 1-2, pp. 116-119, 2006.

[6] A. Esrafili, Y. Yamini, and S. Shariati, "Hollow fiber-based liquid phase microextraction combined with high-performance liquid chromatography for extraction and determination of some antidepressant drugs in biological fluids," Analytica Chimica Acta, vol. 604, no. 2, pp. 127-133, 2007.

[7] B. N. Patel, N. Sharma, M. Sanyal, and P. S. Shrivastav, "Analysis of second-generation antidepressant drug, sertraline and its active metabolite, N-desmethyl sertraline in human plasma by a sensitive and selective liquid chromatography-tandem mass spectrometry method," Journal of Chromatography B, vol. 877, no. 3, pp. 221-229, 2009.

[8] D. S. Jain, M. Sanyal, G. Subbaiah, U. C. Pande, and P. Shrivastav, "Rapid and sensitive method for the determination of sertraline in human plasma using liquid chromatography-tandem mass spectrometry (LC-MS/MS)," Journal of Chromatography B, vol. 829, no. 1-2, pp. 69-74, 2005. 
[9] L. Labat, M. Deveaux, P. Dallet, and J. P. Dubost, "Separation of new antidepressants and their metabolites by micellar electrokinetic capillary chromatography," Journal of Chromatography B, vol. 773, no. 1, pp. 17-23, 2002.

[10] V. Pucci, S. Fanali, C. Sabbioni, and M. A. Raggi, "Separation of eleven central nervous system drugs by capillary zone electrophoresis," Journal of Separation Science, vol. 25, pp. 1096-1100, 2002 .

[11] D. A. Skoog and D. M. West, Principles of Instrumental Analysis, Holt Sounder, Philadelphia, Pa, USA, 1985.

[12] M. I. Walash, F. Belal, N. El-Enany, and H. El-Mansi, "Spectrophotometric determination of the antidepressants sertraline and paroxetine $\mathrm{HCl}$ using 2,4-dinitrofluorobenzene," International Journal of Biomedical Science, vol. 6, no. 3, pp. 252-259, 2010.

[13] A. S. Amin, H. A. Dessouki, M. M. Moustafa, and M. S. Ghoname, "Spectrophotometric methods for sertraline hydrochloride and/or clidinium bromide determination in bulk and pharmaceutical preparations," Chemical Papers, vol. 63, no. 6, pp. 716-722, 2009.

[14] L. I. Bebawy, N. El-Kousy, J. K. Suddik, and M. Shokry, "Spectrophotometric determination of fluoxetine and sertraline using chloranil, 2, 3 dichloro-5, 6 dicyano benzoquinone and iodine," Journal of Pharmaceutical and Biomedical Analysis, vol. 21, no. 1, pp. 133-142, 1999.

[15] I. A. Darwish, "Development and validation of spectrophotometric methods for determination of fluoxetine, sertraline, and paroxetine in pharmaceutical dosage forms," Journal of AOAC International, vol. 88, no. 1, pp. 38-45, 2005.

[16] ICH [Stability Testing of New Drug Substances and Products (Q1AR2)], International Conference on Harmonization, Food and Drug Administration, USA, November 1996 and February 2003.

[17] ICH [Validation of Analytical procedures: methodology (Q2AR1)], International Conference on Harmonization, Food and Drug Admination, USA, November 1996 and November 2005.

[18] A. C. Moffat, M. D. Osselton, and B. Widdop, Clarke s Analysis of Drugs and Poisons, Pharmaceutical Press, London, UK, 2004. 


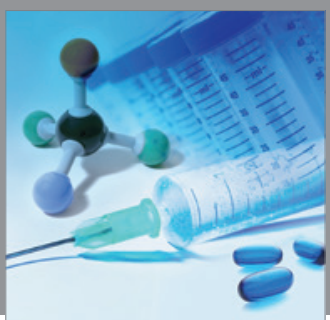

International Journal of

Medicinal Chemistry

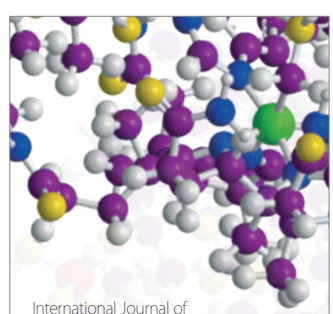

Carbohydrate Chemistry

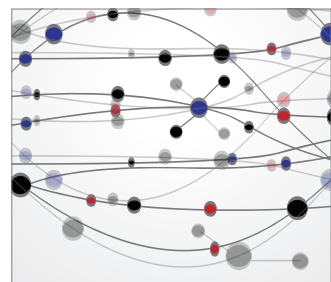

The Scientific World Journal
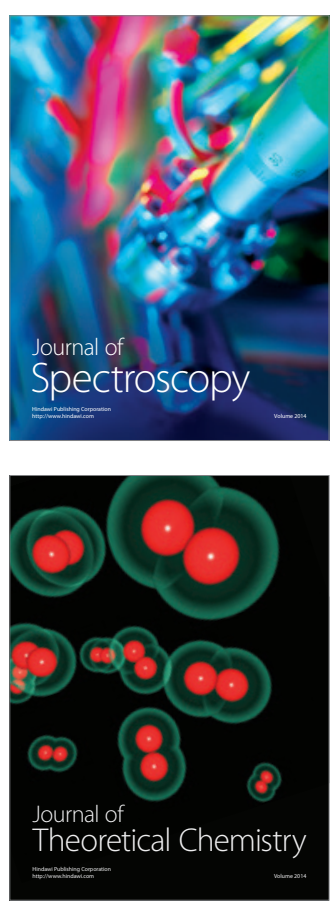
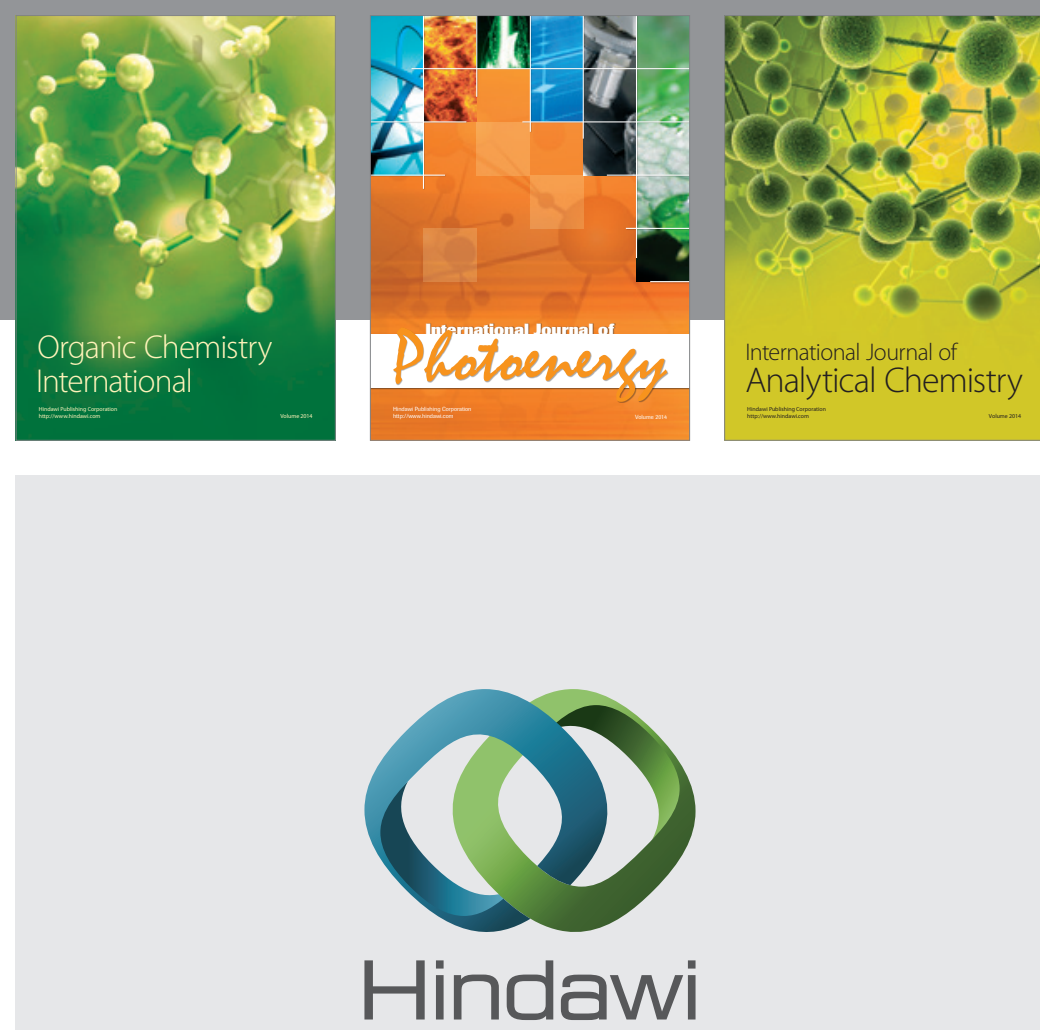

Submit your manuscripts at

http://www.hindawi.com
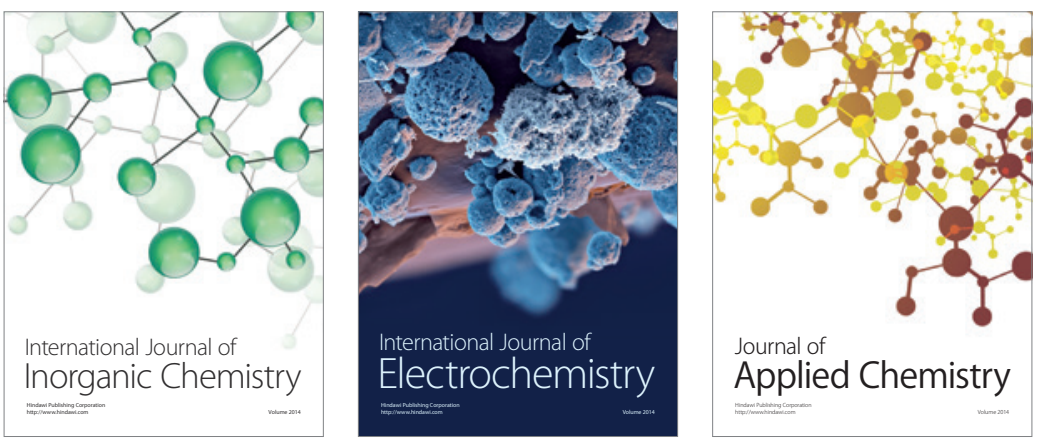

Journal of

Applied Chemistry
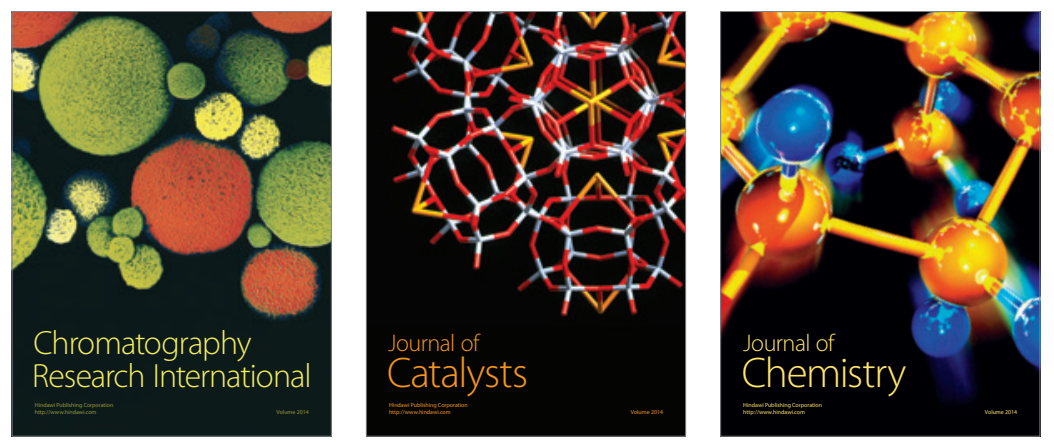
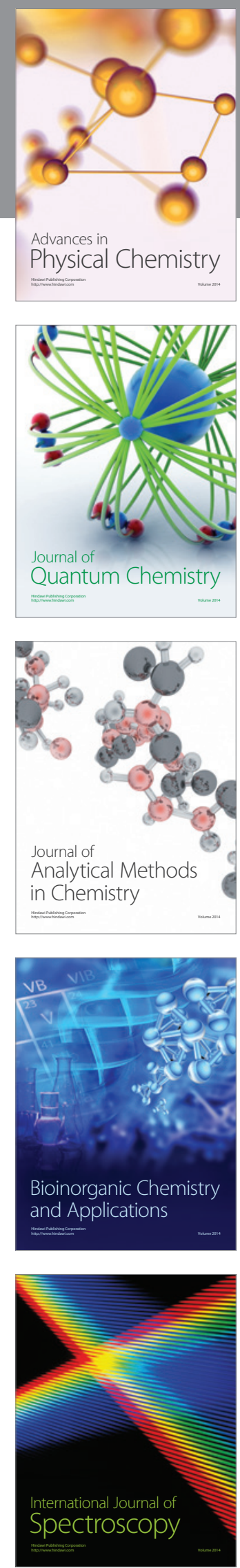